\title{
Identification of H-2d Restricted T Cell Epitope of Foot-and-mouth Disease Virus Structural Protein VP1
}

\author{
Xin-Sheng Liu, Yong-Lu Wang*, Yong-Guang Zhang, Yu-Zhen Fang, Li Pan, Jian-Liang Lu, Peng Zhou, \\ Zhong-Wang Zhang and Shou-Tian Jiang
}

\begin{abstract}
Background: Foot-and-mouth disease (FMD) is a highly contagious and devastating disease affecting livestock that causes significant financial losses. Therefore, safer and more effective vaccines are required against Foot-and-mouth disease virus(FMDV). The purpose of this study is to screen and identify an $\mathrm{H}$-2d restricted T cell epitope from the virus structural protein VP1, which is present with FMD. We therefore provide a method and basis for studying a specific FMDV T cell epitope.
\end{abstract}

Results: A codon-optimized expression method was adopted for effective expression of VP1 protein in colon bacillus. We used foot-and-mouth disease standard positive serum was used for Western blot detection of its immunogenicity. The VP1 protein was used for immunizing BALB/c mice, and spleen lymphocytes were isolated. Then, a common in vitro training stimulus was conducted for potential $\mathrm{H}-2 \mathrm{Dd}, \mathrm{H}-2 \mathrm{Kd}$ and $\mathrm{H}-2 \mathrm{Ld}$ restricted $\mathrm{T}$ cell epitope on VP1 proteins that were predicted and synthesized by using a bioinformatics method. The H-2Kd restricted T cell epitope pK1 (AYHKGPFTRL) and the H-2Dd restricted T cell epitope pD7 (GFIMDRFVKI) were identified using lymphocyte proliferation assays and IFN- $\gamma$ ELISPOT experiments.

Conclusions: The results of this study lay foundation for studying the FMDV immune process, vaccine development, among other things. These results also showed that, to identify viral T cell epitopes, the combined application of bioinformatics and molecular biology methods is effective.

\section{Background}

FMD is an acute, febrile, highly contagious zoonotic disease [1] that is caused by the FMDV and that mainly harms cloven-hoofed animals. The pathogen belongs to the genus FMDV of the small RNA virus branch. Crossprotection tests and serological tests have confirmed that FMDV has seven serotypes, namely O, A, C (European type), Asia 1 (Asia 1 type) and the STA1, STA2, STA3 (South African type) [2]. FMDV antigen has a complex structure and a wide range of antigenic variation, but it does not possess cross protection among reaction types, seven serotypes have a great amount of antigenic difference, which makes it more difficult for vaccine prevention $[3,4]$. Currently, inactivated/

\footnotetext{
* Correspondence: wangyonglumd@yahoo.cn

State Key Laboratory of Veterinary Etiological Biology, National Foot and Mouth Disease Reference Laboratory, Lanzhou Veterinary Research Institute, Chinese Academy of Agricultural Sciences, Lanzhou 730046, China
}

attenuated pathogens or the complete viral antigens are used as a vaccine. The former has a good effect, but has biological safety problems; while the effect of the latter is often very limited. Thus, epitope-based vaccine design has become the priority and hot spot of current FMD vaccine research. At present, there are some more successful reports about research on the FMD epitope vaccine [5-9], but all of these are based on determining $B$ and $\mathrm{T}$ cell epitopes from the FMDV structural and nonstructural proteins. Identification of FMDV epitopes is also a very active area of research in recent years. Previous research has identified a number of effective FMDV epitopes [10-22], which provides important keys for developing epitope vaccines with higher immunogenicity and protective capabilities.

FMDV particles are mainly composed of 4 capsid proteins (i.e., VP1, VP2, VP3 and VP4) with 60 respective copies. The structural protein VP1 contains major 
antigenic sites of the FMDV. The VP1 genes mutate easily, which often leads to toxic antigenic strain and virulence changes. Additionally, it is the main reason for polymorphic and multi-subtype FMDV [23]. Therefore, it is particularly important for developing research on antigen epitopes regarding the FMDV structural protein VP1.

It is generally believed that anti-infection immunity against FMDV is mainly related to high levels of antibodies, but with increased research it has become evident that other parts of the cellular immune response play an important role in protection against FMD. The production of neutralizing antibodies in FMDV infection requires $B$ cell epitopes and $T$ cell epitopes. The vaccine cannot elicit a protective immune response without $\mathrm{T}$ cell epitopes [24]. Cytotoxic T lymphocytes (CTL) are one of the immune cells needed for the body to effectively control viral infection. MHC I molecule restricted antigen-specific CTL responses are important for viral clearance, to control viral replication, and to prevent diffusion during viral infection. Previous studies on FMDV antigen epitopes have mostly concentrated on the study of $\mathrm{B}$ cell epitopes and assistant $\mathrm{T}$ cell epitopes. However there is limited research on FMDV cytotoxic T lymphocyte epitopes and its effect on protection against FMDV. So far, the only discovered cytotoxic T lymphocyte epitopes on the FMDV structural protein VP1 are two pig SLA molecule restricted cytotoxic T lymphocyte epitopes [22]. Therefore, an in-depth study on the FMDV CTL $\mathrm{T}$ cell epitopes has important significance to accurately map CTL epitopes in detail for FMDV. This would illuminate the importance of the cellular immune response, pathogenesis of the FMDV, and provide insight in to developing epitope vaccines.

Therefore, the purpose of this study is to identify CTL $T$ cell epitopes on the FMDV structural protein VP1. This would provide clues and help for future studies. We combined bioinformatic predictions and experimental validation, a method which is widely used and has successfully identified many antigen epitopes, for the screening and identification of $\mathrm{H}-2$ restricted $\mathrm{T}$ cell epitopes on the FMDV structural protein VP1 [25-29]. Additionally, it was used to successfully identify possible CTL T cell epitopes on two FMDV structural proteins VP1.

\section{Results}

VP1 Antigen Protein Cloning, Expression and Immunogenicity Analysis

We obtained the complete sequence of the wild-type FMDV AF/72 strain structural protein VP1 gene through cloning and sequencing. Sequence analysis results revealed that the full length VP1 was successfully cloned with all 639 nucleotides and 213 amino acids that encode the protein. The expression of an exogenous gene in E. coli was controlled by a number of factors, mainly in the transcription and translation stages, and it was also important to affect protein expression using varying passwords. Rare codons in the sequence were changed into E. coli advantage codons, thereby optimizing the codons with the wildtype VP1 gene as reference sequences. Additionally, the adaptation index of the codons was optimized, and the GC content was balanced. The synthetic optimization sequence was connected with the vector pET28a, and BL21 (DE3) host bacteria were transformed for protein expression. Concurrently, we optimized and confirmed the optimal expression conditions for the expression of recombinant proteins. The results showed that the recombinant strain optimally expressed the protein after being induced with $1 \mathrm{~mol} / \mathrm{L}$ IPTG at $37^{\circ} \mathrm{C}$ for $3 \mathrm{~h}$. After being purified by the affinity layer, VP1 protein was identified by SDS-PAGE electrophoresis, and the results showed that VP1 protein was successfully and highly expressed in E. coli with a molecular weight of approximately $33 \mathrm{kDa}$, which was consistent with the expected size (Figure 1). Western blot analysis results showed that the VP1 protein generated under conditions promoting optimal expression can generate a specific reaction with FMDV type-A standard positive sera, which further confirmed that the VP1 protein that was generated under



Figure 1 SDS-PAGE Results of VP1 Protein. These results show that the structural protein VP1 after optimal expression has the size of $33 \mathrm{kDa}$, which is consistent with the expected size. 1: Uninduced control; 2: 3 hour induction; 3: Disintegrating liquid with ultrasonic; 4: Clarifying after disintegrating liquid with ultrasonic and centrifugation; 5: purifying sample solution with $\mathrm{Ni}$ Column, dissolved inclusion bodies; 6: Purifying flowing liquid with $\mathrm{Ni}$ Column; 7: Purifying Ni-Denature-8.0 wash solution with Ni Column; 8: Purifying Ni-Denature-6.0 wash solution with Ni Column; 9: Purifying Ni-Denature-4.0 equate with Ni Column; 


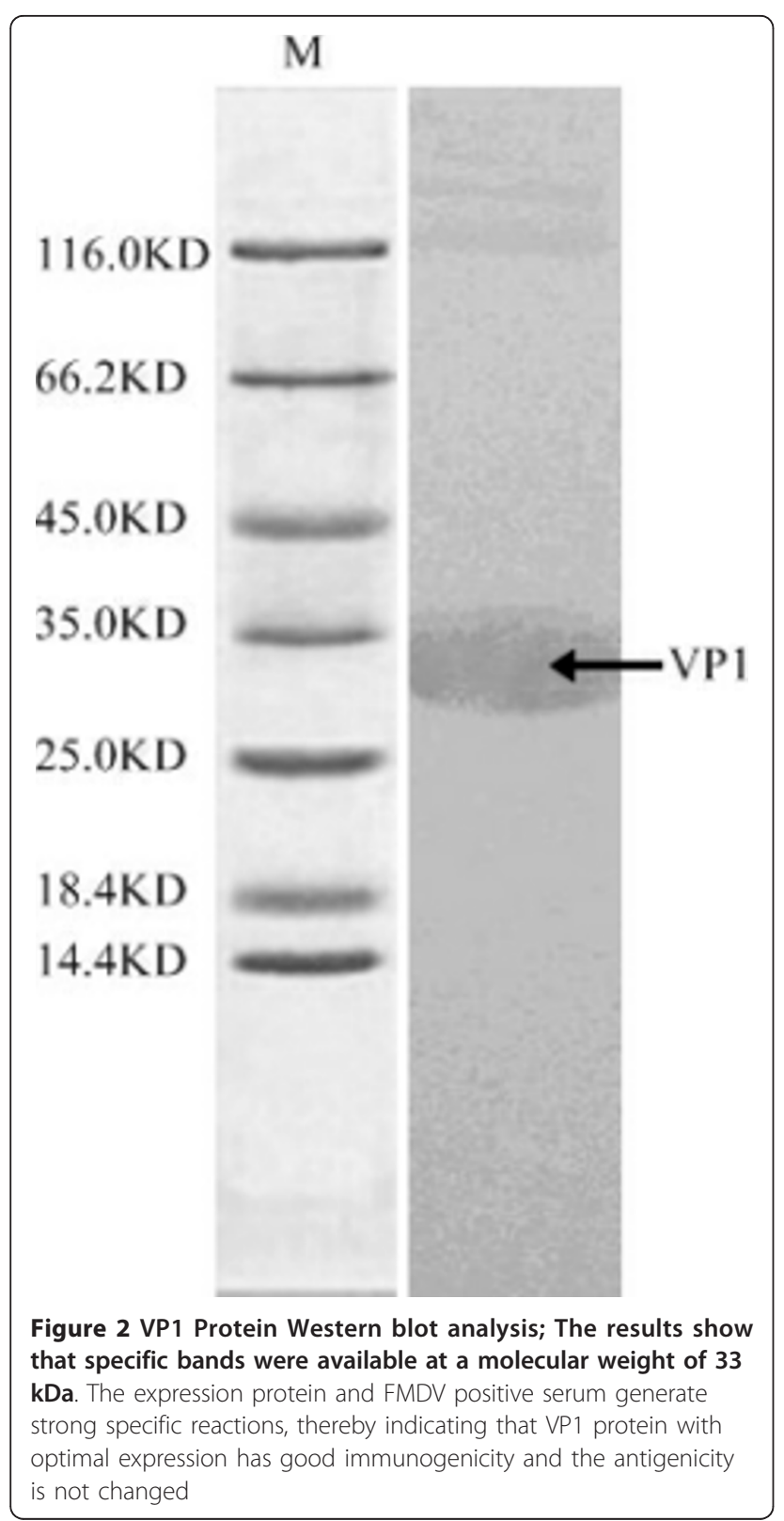

conditions promoting optimal expression was correctly expressed in E. coli and that it has acceptable immunogenicity (Figure 2).

\section{$\mathrm{CD}^{+} \mathrm{T}$ Cell Epitope Prediction Results and Selection}

CTL epitope prediction refers to peptides that can be predicted by looking for the rule of combining antigen peptide with specific MHC molecules. BIMAS algorithm experimentally measured peptide-MHC complexes and established the grade affinity matrix with the dissociation half-life under $\mathrm{pH} 6.5$ in a $37^{\circ} \mathrm{C}$ environment, thus predicting $\mathrm{MHC}$ restricted epitopes that have been successfully applied to the identification of a wide range of CTL epitopes [30]. This study utilizes the software to predict the $\mathrm{H}-2 \mathrm{~d}$ restricted cytotoxic $\mathrm{T}$ cell epitopes of FMDV AF/72 strain structural protein VP1. A total of $30 \mathrm{H}-2 \mathrm{Dd}, \mathrm{H}-2 \mathrm{Kd}$ and $\mathrm{H}-2 \mathrm{Ld}$ restricted $\mathrm{T}$ cell epitopes were identified by the highest score and from those 10 peptides were selected as the candidates (Table 1).

\section{Lymphocyte In Vitro Proliferation Experiment for Identifying $\mathrm{CD}^{+} \mathrm{T}$ Cell Epitopes}

The MTS colorimetric method was used to verify $\mathrm{CD} 8^{+}$ $\mathrm{T}$ lymphocyte proliferation after mouse splenic lymphocytes were stimulated with a candidate epitope peptide section. Significant lymphocyte proliferation occurred in the positive control group, but no lymphocyte proliferation was detected in the negative control group. In the experimental group, the $\mathrm{H}-2 \mathrm{Kd}$ restricted $\mathrm{T}$ cell epitope candidate peptide $\mathrm{pK} 1$ and the $\mathrm{H}-2 \mathrm{Dd}$ restricted $\mathrm{T}$ cell epitope candidate peptide section pD7 stimulated the proliferation of mouse lymphocytes (SI>2). Additionally,

Table 1 Amino acid sequence of the predicted VP1 protein $\mathrm{CD}^{+} \mathrm{T}$ cell epitopes and BIMAS scores

\begin{tabular}{|c|c|c|c|c|}
\hline $\begin{array}{c}\text { MHC- } \\
\text { restriction }\end{array}$ & Code & $\begin{array}{c}\text { Start } \\
\text { Position }\end{array}$ & $\begin{array}{c}\text { Subsequence Residue } \\
\text { Listing }\end{array}$ & Score \\
\hline \multirow[t]{10}{*}{$\mathrm{H}-2 \mathrm{Ld}$} & pL1 & 103 & NPTAYHKGPF & 300 \\
\hline & pL2 & 117 & LPYTAPHRVL & 150 \\
\hline & pL3 & 89 & VPNGAPETAL & 150 \\
\hline & pL4 & 9 & DPVTTTVENY & 72 \\
\hline & pL5 & 121 & APHRVLATVY & 60 \\
\hline & pL6 & 110 & GPFTRLALPY & 60 \\
\hline & pL7 & 45 & QSPTHVIDLM & 37.5 \\
\hline & pL8 & 42 & IPSQSPTHVI & 30 \\
\hline & pL9 & 158 & LPASFNFGAI & 30 \\
\hline & pL10 & 188 & RPLLAVKVTS & 30 \\
\hline \multirow[t]{10}{*}{$H-2 D d$} & pD1 & 138 & TGNAGRRGDL & 30 \\
\hline & pD2 & 109 & KGPFTRLALP & 24 \\
\hline & pD3 & 141 & AGRRGDLGS & 3 \\
\hline & pD4 & 62 & VGALLRAATY & 10 \\
\hline & pD5 & 45 & QSPTHVIDLM & 7.2 \\
\hline & pD6 & 41 & KIPSQSPTHV & 7.2 \\
\hline & pD7 & 33 & GFIMDRFVKI & 6 \\
\hline & pD8 & 116 & ALPYTAPHRV & 6 \\
\hline & pD9 & 56 & THQHGLVGAL & 3 \\
\hline & pD10 & 197 & SQDRHKQRII & 20 \\
\hline \multirow[t]{10}{*}{$\mathrm{H}-2 \mathrm{Kd}$} & pK1 & 106 & AYHKGPFTRL & 3456 \\
\hline & pK2 & 33 & FIMDRFVKI & 1920 \\
\hline & pK3 & 163 & NFGAIRATVI & 1152 \\
\hline & pK4 & 71 & YYFSDLEIW & 720 \\
\hline & pK5 & 70 & TYYFSDLEIV & 600 \\
\hline & pK6 & 184 & LYCPTPLLAV & 600 \\
\hline & pK7 & 204 & RIIAPAKQLL & 115.2 \\
\hline & pK8 & 52 & DLMQTHQHGL & 80 \\
\hline & pK9 & 77 & EIWRHDDNL & 80 \\
\hline & pK10 & 175 & LLVRVKRAEL & 80 \\
\hline
\end{tabular}


higher transformation capacity induced by lymphocytes could be shown, while the other candidate epitope peptide sections cannot effectively stimulate the proliferation of mouse lymphocytes sensitized by VP1 protein. In addition, these peptides were unable to stimulate the lymphocyte proliferation of PBS immunized mice (SI $<2$ ), (Figure 3). These results suggest that peptide section pK1 (AYHKGPFTRL) and pD7 (TGESADPVTT) may be epitopes of VP1's protein-specific CTL.

\section{INF- $\gamma$ ELISPOT Experiments Further Confirmed the Results of the Proliferation Experiments}

IFN- $\gamma$ secretion by cells was checked using ELISPOT, which further validated the results of the $\mathrm{T}$ cell proliferation assays. The test results show that mouse spleen lymphocyte holes stimulated by $\mathrm{H}-2 \mathrm{Kd}$ restricted $\mathrm{T}$ cell epitope pK1 (AYHKGPFTRL) and H-2Dd restricted T cell epitope pD7 (TGESADPVTT) can be seen as lymphocyte colonies within increasing IFN- $\gamma$ secretion. Mouse splenic lymphocytes stimulated by other peptide sections and non-stimulated mouse splenic lymphocytes were used for detecting individual lymphocyte colony IFN- $\gamma$ secretion or for detecting lymphocyte colonies that did not secrete IFN- $\gamma$ (Figures 4 and 5). Anova showed that there were significant differences $(P<0.01)$ between the spot count from mouse splenic lymphocytes that were stimulated by peptide sections pK1 and pD7 compared with lymphocytes stimulated with other peptide sections. These results confirmed the observations in the $\mathrm{T}$ cell proliferation experiments and further confirmed that peptide sections $\mathrm{pK} 1$ and $\mathrm{pD} 7$ may be VP1 protein-specific CTL epitopes.

\section{Discussion}

Viral antigens are cleaved into oligopeptides of small molecules, which bind MHC-I molecules forming "antigen-MHC-I complexes". These complexes present viral proteins on the surface of antigen-presenting cells

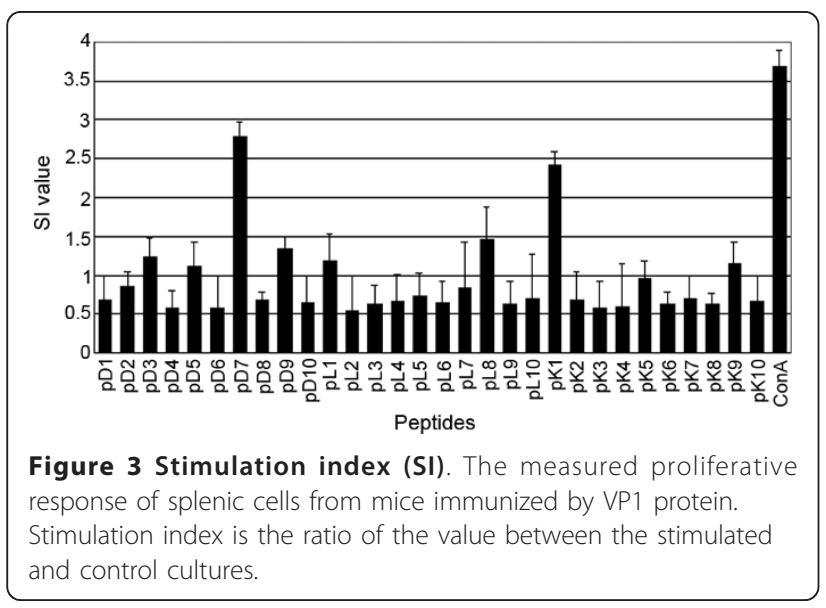

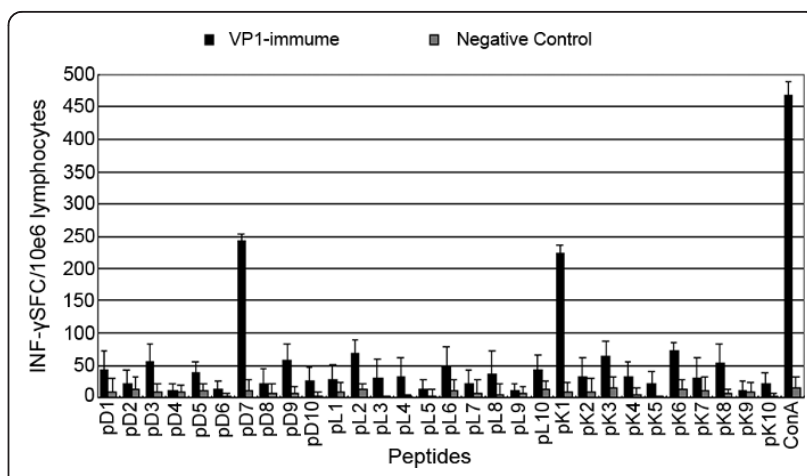

Figure 4 IFN- $\gamma$ ELISPOT. The statistical results from the ELISPOT of immunized Balb/c mice splenic lymphocyte after stimulation with peptides by Analysis of Variance (ANOVA). The negative control represents lymphocytes plated with RPMI 1640 without peptides. The experimental groups are lymphocytes plated with peptides. Asterisks indicate statistical significance compared with the value of wells without peptides $(P<0.01)$

allowing $\mathrm{CD}^{+} \mathrm{T}$ cells to specifically recognize the viral protein through their expression of the viral specific TCR. These viral peptides that are presented on MHC I to $\mathrm{CD} 8^{+} \mathrm{T}$ cells represent CTL epitopes that can initiate an anti-viral response [30]. Identification of CTL epitopes has been a focus of immunology because it is the key for the research and development of immunodiagnostics, immunotherapy and new vaccines. Additionally, it is helpful for exploring and clarifying the pathogenesis of microorganisms and the subsequent immune response [31-33]. CTL play a critical role in the antiviral response to infection in the body. However, previous studies investigating the immune response against FMD have provided little understanding of the protective role of cell cytotoxic lymphocytes against the FMDV. The research on epitopes of the FMDV has mainly focused on the study of B cell epitopes, which are associated with humoral immunity, as well as Th cell epitopes that promote the generation of high-level protective antibodies. These studies have overlooked the importance of CTL epitopes as shown with only one study on CTL epitopes of FMDV [22]. The only research report of FMDV CTL epitopes predicts possible CTL epitopes, but does not have in vitro tests to accurately verify these CTL epitopes as immunogenic.

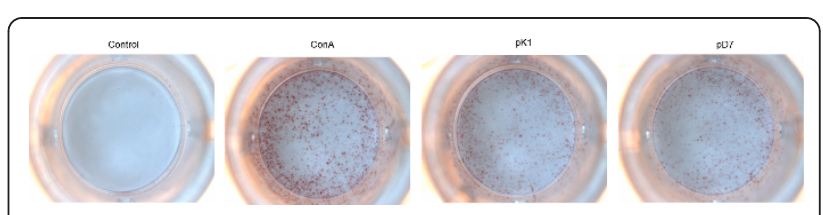

Figure 5 The ELISPOT results of immunized Balb/c splenic lymphocytes after stimulation with peptides, ConA and two positive peptides (pk1: $\mathrm{H}-2 \mathrm{~K}^{\mathrm{d}}$ restricted, $\mathrm{pD7}$ : $\mathrm{H}-2 \mathrm{D}^{\mathrm{d}}$ restricted). 
Therefore, our work has provided a comprehensive and detailed description of FMDV epitope mapping and has increased our understanding of the protective effects of cytotoxic lymphocytes against FMDV.

We identified candidate epitopes using bioinformatics, and candidate epitopes were scored using an epitope prediction software. Potential epitopes were determined based on their scores and the secretion of cytokines induced by the potential epitopes. As opposed to the commonly used $\mathrm{T}$ cell epitope identification methods, such as synthetic overlapped peptide screening method, bioinformatics technology was used to predict and analyze advantageous antigenic epitopes of the targeted protein. The epitopes can be pre-determined, thereby reducing blindness of study. Additionally, the epitopes can be validated using molecular biology, which increases the likelihood that the predicted epitopes are authentic. However, the results of the test suggest that the software prediction accuracy is low and does not completely and truly reflect actual epitopes. Therefore, it should only be used as a reference.

Many viruses have a significantly different function regarding the frequency of their codon usage compared to their host cell's codons. Viral genes may alter the expression of targeted proteins due to different codon biases when being expressed in host cells [34-36]. Therefore, we adopted a coded optimization expression method for the expression of VP1 protein in E. coli and utilized this method for preparing the FMDV structural protein VP1 from the mouse immune antigen to prevent the possibility that the FMDV structural protein VP1 alters the expression of the VP1 protein due to different codon biases in the E. coli cell expression process. Otherwise, this could result in changing identified T-cell epitopes and could limit the accuracy and efficiency of the expression of VP1. Western blot analysis showed that the VP1 protein produced under conditions that promote optimal expression can generate specific reactions with FMDV type-A standard positive sera. Additionally, we proved that VP1 protein produced under conditions that promote optimal expression was correctly expressed in E. coli and maintained immunogenicity, ensuring that the $\mathrm{T}$ cell epitope amino acid sequences identified in the following experiments were correct and effective.

VP1 protein with incomplete Freund's adjuvant with the same dose was used to boost the immune response 2 weeks after the primary immunization. Following the initial boost, we strengthened the immunity once every two weeks. The immunization method with a total of 3 times of strengthening immunity ensures that mice after immunization are adequate for inducing and generating enough long-term memory $\mathrm{T}$ cells. This was necessary to ensure that there were a sufficient number of $\mathrm{T}$ lymphocytes available for in vitro stimulation and to ensure more accurate test results.

Epitope selection is based on a number of factors, such as the composition of $\mathrm{T}$ cells and the affinity between the epitope and MHC molecules [37,38]. The frequency of $\mathrm{CD} 4^{+} \mathrm{T}$ cells that secrete IFN- $\gamma$ is increased with the increase in mononuclear cells. This is mediated by monocyte-derived cytokine-production $[39,40]$. Epitopes can be presented to $\mathrm{CD}^{+} \mathrm{T}$ cells through monocytes. Additionally, $\mathrm{CD}^{+} \mathrm{T}$ cells also secrete IFN- $\gamma$ upon activation. In this study, the composition of the splenic lymphocytes for each mouse was the same with the constant amount, thus eliminating errors that may be caused by $\mathrm{CD} 4^{+} \mathrm{T}$ cell secretion of IFN- $\gamma$. In this study, small peptides composed of ten amino acids identified through prediction synthesis were used to carry out in vitro stimulations of splenic lymphocytes from immunized mice. The ability of candidate epitope peptide sections to stimulate and activate mouse $\mathrm{T}$ lymphocytes were evaluated for cell quantity changes and cell factor secretion, respectively through $\mathrm{T}$ cell proliferation assays and IFN- $\gamma$ Elispot experiments. The results showed that the $\mathrm{H}-2 \mathrm{Kd}$ restricted $\mathrm{T}$ cell candidate epitope peptide section pK1 (AYHKGPFTRL) and the $\mathrm{H}$-2Dd restricted $\mathrm{T}$ cell candidate peptide epitope pD7 (TGESADPVTT) can effectively induce activated chicken $\mathrm{T}$ lymphocytes to produce a $\mathrm{T}$ cellular response. Therefore these two candidate peptide epitopes may be the mouse $\mathrm{H}-2 \mathrm{~d}$ restricted cytotoxic $\mathrm{T}$ cell epitopes. The experimental results also indicate that although the two epitopes have different restrictions, they may produce $T$ cell responses of the same type. However, this test currently only validated epitope prediction and the ability of $\mathrm{T}$ lymphocytes to react to the epitope. However, further tests are required to verify whether these epitopes are immunogenic. Two CTLs that were identified by these experiments could not be used because they were not the natural hosts of FMDV, such as pigs, cattle, sheep and other cloven-hoofed animals. But the process and results of these experiments provide initial evidence for studying the possible development of an epitope vaccine against FMDV. Additionally, this study is beneficial in demonstrating the effects of cytotoxic lymphocytes in protecting against FMD in their response against the FMDV, which is possible through the identification of CTL epitopes in mice, and this is a normal model for the study of FMDV.

FMDV strain AF/72 that was used in these experiments is a vaccine strain that has been used in developing a FMD vaccine. This strain has demonstrated good immune effects. The study selected the structural protein VP1 of strains AF/72 as the protein used to study epitopes because the structural protein VP1 contains the major antigenic sites of the foot-and-mouth disease 
virus and is the main antigen of the FMDV [41-43]. Sequence homology analysis of the AF/72 strain structural protein VP1 showed that, compared with the FMDV A/NM/XZ/64 (AJ131664) strains, A/NM/EL/60 (AJ131664) strain and GS/LX/62 (AJ131666) strain, which are isolated in China, showed there was a nucleotide homology of more than $97 \%$. Additionally, the nucleotide sequences of the zones of the two identified CTL epitopes did not change. Therefore, the two CTL epitopes identified in the experiment are representative.

The successful use of biology software for prediction was considered when targeted epitopes were selected in the experimental design. Additionally, FMDV molecular biology characteristics were rarely determined, and the antigen epitope on the VP1G-H ring that had previously been identified were not identified in these experiments. This suggests that the characteristics of this virus's molecular biology and previous study results should be considered on the basis of software prediction in future epitope analysis tests.

\section{Conclusions}

These experiments predicted 30 potential CTL epitopes on structural protein VP1 through bioinformatics, thus reducing the scope for the identification of potential epitopes and improving the accuracy of the experiments. Immunological experimental techniques were utilized to carry out the in vitro identification of the screened candidate epitopes that had been predicted. Finally, two murine $\mathrm{H}-2 \mathrm{~d}$ restricted cytotoxic $\mathrm{T}$ cell epitopes on the FMDV VP1 structural protein were identified, including $\mathrm{H}-2 \mathrm{Kd}$ restricted $\mathrm{T}$ cell epitopes pK1 (AYHKGPFTRL) and H-2Dd restricted T-cell epitope pD7 (TGESADPVTT) from 106 to 115 amino acids and from 4 to 13 amino acids on VP1, respectively. This study provides direct evidence demonstrating the need for further clarification of the FMDV T cell epitopes. Additionally, it establishes research methods for studying other viral $\mathrm{T}$ cell epitopes.

\section{Materials and methods Virus and mouse}

FMDV AF/72 strains were separated, identified and stored by our laboratory. Female SPF level six-week-old BALB/c mice were purchased from Lanzhou Institute of Biological Products and were fed in clean level environment.

\section{VP1 Antigen Protein Preparation}

FMDV virus strain genomic group RNA was taken as a template. We used a pair of primers (upstream primer: 5'-CACAAATGTACAGGGATGGGT-3' and downstream primer: 5'-GACATGTCCTCCTGCATCT-3'). Complete nucleotide sequence of VP1 was obtained through reverse transcription and PCR extension. The recovered PCR products were connected to pGEM-T easy vector. The competent cell JM109 was transformed, and the plasmid was extracted after blue-white screening; moreover, the clone, which was identified as positive through PCR and whose enzyme was cut, was sent to Dalian TaKaRa Biotechnology Co., Ltd for sequencing.

We followed the E. coli codon bias to reform codons of wild-type VP1 genes and sent them to Shanghai Sangon Biotech Co., Ltd for synthesis under the conditions that there were no changes in the amino acid sequences of VP1 protein. This ensured that VP1 expression was accurate and efficient, thereby enabling the mouse immune program to be of a high level of quality. Synthesis genes were connected with vector pET28a and target protein expression was induced after the BL21 (DE3) host strain was transformed. Affinity chromatography columns were used for purification. SDS-PAGE and Western blotting was used for checking the molecular size and immunogenicity of the VP1 protein after expression conditions were varied compared with wildtype VP1 protein.

\section{Epitope Peptide Prediction and Preparation}

The BIMAS program http://www-bimas.cit.nih.gov/molbio/hla_bind[44] was used for analyzing and predicting potential $\mathrm{H}-2 \mathrm{Dd}, \mathrm{H}-2 \mathrm{Kd}$ and $\mathrm{H}-2 \mathrm{Ld}$ restricted CTL epitopes on the VP1 protein according to the VP1 amino acid sequence. We identified ten $\mathrm{H}-2 \mathrm{Dd}, \mathrm{H}-2 \mathrm{Kd}$ and $\mathrm{H}-$ $2 \mathrm{Ld}$ restricted $\mathrm{T}$ cell epitopes that scored the highest. In total, 30 peptides were selected and sent to Shanghai Sangon Biotech Co., Ltd for synthesis. The purity of all synthetic peptides was higher than $95 \%$ based on quantifications from RP-HPLC measurements. The peptides were reconstituted with a certain amount of DMSO solution and RPMI1640 at a concentration of $1 \mathrm{mmol} / \mathrm{L}$, and then the solution was packed and stored at $-70^{\circ} \mathrm{C}$.

\section{Mice Immunity}

After affinity chromatography purification, VP1 protein was fully mixed with Freund's complete adjuvant with equal volume. SPF BALB/c mice were subcutaneously immunized with multi-point abdominal injections with an initial immunization dose of $100 \mu \mathrm{g} /$ mouse. Booster immunizations were carried out 2 weeks later. Incomplete Freund's adjuvant was used during the booster immunization once every two weeks for an additional three times. VP1 protein was replaced with PBS for mice in the control group using the same immunization procedures. All animal studies were approved by the Review Board of Lanzhou Veterinary Research Institute, Chinese Academy of Agricultural Sciences (Permission number: SYXK-GAN-2004-0005). The mice used in this 
study were kindly bred during the experiment and euthanasia was carried out at the end of the experiment to reduce suffering.

\section{Preparation of Splenic Lymphocytes}

After the immunizations were finished, mice were euthanized and spleens were harvested using sterile technique, and $3 \mathrm{~mL}$ of EZ-Sep TM Mouse $1 \times$ lymphocyte isolation was placed in a $35 \mathrm{~mm}$ Petri dish with a 200 nylon mesh fixed on the dish. Following harvest, we made a single cell suspension of the mouse spleen by gently grinding the spleen using a syringe piston. The single cell suspension was maintained in 1640 medium at $0.5 \mathrm{~mL}$. The cell suspension was centrifuged at $800 \mathrm{~g}$ for 30 minutes. The lymphocyte cell layer was isolated, washed in $10 \mathrm{~mL}$ of 1640 medium, and centrifuged at $250 \mathrm{~g}$ for 10 minutes. Supernatant was decanted and the cells were resuspended in serum-free media. Lymphocytes were resuspended in 1640 medium at a cell density of $10^{7}$ cells $/ \mathrm{mL}$ and were cultured at $37^{\circ} \mathrm{C}$ in $5 \% \mathrm{CO} 2$.

\section{T Cell Proliferation Assay}

One hundred microliters of the prepared lymphocyte cell suspension $\left(10^{7}\right.$ cells $\left./ \mathrm{mL}\right)$ was added to each well in a 96-well plate. Following the plating of the cell suspension, the synthetic peptide $(30 \mu \mathrm{g} / \mathrm{mL})$ was added with a final volume of $200 \mu \mathrm{L} /$ well. Three parallel wells were made for each peptide section. RPMI 1640 medium was added in negative control wells without an additional stimulus. ConA was used for stimulation of the positive control group. Additionally, three parallel wells were set up with the final volume of $200 \mu \mathrm{L} /$ well. The cultures were incubated at $37^{\circ} \mathrm{C}$ in a $5 \% \mathrm{CO} 2$ incubator for $72 \mathrm{~h}$. We added $20 \mu$ CellTiter $96^{\circledR}$ AQueous One Solution Reagent to each well 4 hours before the end of the culture. Following the addition of this reagent the cells were cultured at $37^{\circ} \mathrm{C}$ in a $5 \% \mathrm{CO} 2$ incubator. After incubation, the absorbance was checked at $490 \mathrm{~nm}$. The mean of the three duplicate wells $(x \pm s)$ was calculated, and the results were expressed as the stimulation index (SI) $\left(\mathrm{SI}=\mathrm{A}_{490}\right.$ mean of experimental group $/ \mathrm{A}_{490}$ mean of negative control group). A positive result on the stimulation index was considered if $\mathrm{SI} \geq 2$.

\section{IFN- $\gamma$ ELISPOT Experiment}

PBS diluted coating antibody $(50 \mu \mathrm{L})$ was added to each well on the PVDF 96-well plate. The plate was coated overnight at $4^{\circ} \mathrm{C}$. The coating liquid was decanted and the plate was washed twice with PBS. The plate was dried on the sterile absorbent paper following the final wash. PBS $(1 \times)$ diluted blocking solution was added $(200 \mu \mathrm{L} /$ well $)$ and sealed at $37^{\circ} \mathrm{C}$ for $1 \mathrm{~h}$. The blocking solution was decanted. The pre-prepared suspension of lymphocytes $(100 \mu \mathrm{l}$ at a concentration of $10^{7}$ cells $\left./ 100 \mu \mathrm{l}\right)$ was added to each well. Synthetic peptides $(10 \mu \mathrm{l}$, with a final concentration of $30 \mu \mathrm{g} /$ $\mathrm{mL}$ ) were added to the test group with three parallel wells prepared for each peptide. ConA $(10 \mu \mathrm{g} / \mathrm{mL})$ was added to the positive control group, but the negative control group received no added stimulus. The plate was covered after all the samples were added. It was placed in a carbon dioxide incubator and cultured for $24 \mathrm{~h}$ at $37^{\circ} \mathrm{C}$. The cells and medium in the wells were decanted after incubation. Ice-cold deionized water $(200 \mu \mathrm{L} /$ well $)$ was added. The plate was incubated in an ice bath for $10 \mathrm{~min}$ at $4^{\circ} \mathrm{C}$. PBST $(200 \mu \mathrm{L})$ was added in each well. After being washed five times, we added diluted biotinylated detection antibody $(100 \mu \mathrm{L})$ to each well, which were incubated for $1 \mathrm{~h}$ at $37^{\circ} \mathrm{C}$. Labeled detection antibody was incubated and washed. Then we added diluted HRP-avidin $(100 \mu \mathrm{L})$ to each well, which was incubated at $37^{\circ} \mathrm{C}$ for 1 hour. Chromogenic reagent $(100 \mu \mathrm{L})$ was added to each well after the above steps and washing. The plate was statically placed for $30 \mathrm{~min}$ at room temperature in a sun-shading place. After spots grew to a suitable size, the plate was washed with deionized water 2 times, and then the development process was stopped. The ELISPOT plate was placed in the automatic reading meter. The appropriate parameters were adjusted, spots were counted, and various parameters of the spots were recorded for statistical analysis. The results of the test were analyzed through variance analysis $t$ tests. The differences were considered significant if $\mathrm{P}<0.05$, and the difference was prominent if $\mathrm{P}<0.01$.

\section{Abbreviations}

FMDV: foot-and-mouth disease virus; IFN- $\gamma$ : interferon- $\gamma$; STA: South African type; CTL:Cytotoxic T lymphocytes; MHC: major histocompatibility complex; SLA: Swine lymphocyte antigen;IPTG: Isopropyl $\beta$-D-1-thiogalactopy ranoside; SDS-PAGE: Sodium Dodecyl Sulfate - Polyacrylamide gel electrophoresis; ConA: Concanavalin A; SFC: Spot-forming cells;ELISPOT: Enzyme-linked immunospot

\section{Acknowledgements}

This study was financially supported by the National High Technology Research and Development Program of China (863 Program) (No. 2011AA10A211) and Ministry of Agriculture' Special Funds for Scientific Research on Public Causes (No.201203039).

Authors' contributions

XSL and YLW conceived of the study. XSL Cloning and expressed VP1 genes, performed lymphocyte in vitro proliferation experiment and INF- $\gamma$ ELISPOT experiments, analyzed the results and drafted the manuscript; YLW and YGZ supervised the research, analyzed the results and helped draft the manuscript; YZF and LP visualized the data. JLL, PZ, ZWZ and STJ assisted with data analysis and prepare the experiment. Manuscript is approved by all authors for publication.

\section{Competing interests}

The authors declare that they have no competing interests

Received: 24 December 2010 Accepted: 7 September 2011 Published: 7 September 2011 


\section{References}

1. Xiao C, Rajput Zl, Hu S: Improvement of a commercial foot-and-mouth disease vaccine by supplement of Quil A. Vaccine 2007, 25(25):4795-4800.

2. Carrillo C, Tulman ER, Delhon G, Lu Z, Carreno A, Vagnozzi A, Kutish GF, Rock DL: Comparative genomics of foot-and-mouth disease virus. J Virol 2005, 79:6487-6504.

3. Kitching RP: Global epidemiology and prospects for control of foot-andmouth disease. Curr Top Microbiol Immunol 2005, 288:133-148.

4. Knowles NJ, Samuel AR: Molecular epidemiology of foot-and-mouth disease virus. Virus Research 2003, 91:65-80.

5. Bittle JL, Houghten RA, Alexander $H$, Shinnick TM, Sutcliffe JG, Lerner RA Protection against foot-and-mouth disease by immunization with a chemically synthesized peptide predicted from the viral nucleotide sequence. Nature 1982, 298(5869):30-33.

6. DiMarchi R, Brooke G, Gale C, Cracknell V, Doel T, Mowat N: Protection of cattle against foot-and-mouth disease by a synthetic peptide. Science (New York, NY) 1986, 232(4750):639-641.

7. Kitson JD, Burke KL, Pullen LA, Belsham GJ, Almond JW: Chimeric polioviruses that include sequences derived from two independent antigenic sites of foot-and-mouth disease virus (FMDV) induce neutralizing antibodies against FMDV in guinea pigs. Journal of Virology 1991, 65(6):3068-3075.

8. Wong HT, Cheng SC, Chan EW, Sheng ZT, Yan WY, Zheng ZX: Plasmids encoding foot-and-mouth disease virus VP1 epitopes elicited immune responses in mice and swine and protected swine against viral infection. Virology 2000, 278(1):27-35.

9. Rodriguez LL, Barrera J, Kramer E, Lubroth J, Brown F, Golde WT: A synthetic peptide containing the consensus sequence of the $\mathrm{G}-\mathrm{H}$ loop region of foot-and-mouth disease virus type-O VP1 and a promiscuous T-helper epitope induces peptide-specific antibodies but fails to protect cattle against viral challenge. Vaccine 2003, 21(25-26):3751-3756.

10. Collen T, DiMarchi R, Doel TR: A T cell epitope in VP1 of foot-and-mouth disease virus is immunodominant for vaccinated cattle. J Immunol 1991, 146(2):749-755.

11. Rodriguez A, Saiz JC, Novella ZS: Antigenic specificity of porcine T cell response against foot-and- mouth disease virus structural proteins: identification of T helper epitopes in VP1. Virology 1994, 205:24-33.

12. Zamorano P, Wigdorovitz A, Chaher MT: Recognition of B and T cell epitopes by cattle immunized with a synthetic peptide containing the major immunogenic site of VP1 FMDV 01 Campos. Virology 1994, 201(2):383-387.

13. van Lierop MJ, Wagenaar JP, van Noort JM, Hensen EJ: Sequences derived from the highly antigenic VP1 region 140 to 160 of foot-and-mouth disease virus do not prime for a bovine T-cell response against intact virus. J Virol 1995, 69:4511-4514.

14. Wang JL, Liu MQ, Han J: A peptide of foot-and-mouth disease virus serotype Asia1 generating a neutralizing antibody response, and an immunostimulatory peptide. Vet Microbiol 2007, 125:224-231.

15. Toja M, Escarmís C, Domingo E: Genomic nucleotide sequence of a footand-mouth disease virus clone and its persistent derivatives. Implications for the evolution of viral quasispecies during a persistent infection. Virus Res 1999, 64(2):161-171.

16. Blanco E, McCullough K, Summerfield A: Interspecies major histocompatibility complex-restricted Th cell epitope on foot-and-mouth disease virus capsid protein VP4. Virol 2000, 74(10):4902-4907.

17. Filgueira MP, Wigdorovitz A, Romera A: Detectionand characterization of functional T-Cell epitopes on the structural proteins V2, VP3, and VP4 of foot and mouth disease virus O1Campos. Virology 2000, 271:234-239.

18. Foster M, Cook A, Cedillo L, Parkhouse RM: Serological and cellular immune responses to non-structural proteins in animals infected with FMDV. Vet Q 1998, 20(Suppl 2):S28-S30.

19. Blanco E, Garcia-Briones M, Sanz-Parra A: Identification of T-cell epitopes in nonstructural proteins of foot-and-mouth disease virus. Virol 2001, 75(7):3164-3174

20. García-Briones, Blanco Esther, Chiva Cristina: Immunogenicity and T cell recognition in swine of foot-and-mouth disease virus polymerase 3D. Virology 2004, 322:264-275.

21. Gerner Wilhelm, Denyer SMichael, Takamatsu Haru-Hisa: Identification of novel foot-and-mouth disease virus specific T-cell epitopes in $\mathrm{c} / \mathrm{c}$ and $\mathrm{d} /$ d haplotype miniature swine. Virus Research 2006, 121:223-228.
22. Gao Feng-Shan, Fang Qin-Mei, Li Yun-Gang, Li Xin-Sheng, Hao Hui-Fang, Xia Chun: Reconstruction of a swine SLA-I protein complex anddetermination of binding nonameric peptides derived from the footand-mouth disease virus. Veterinary Immunology and Immunopathology 2006, 113:328-338

23. Mason WPeter, Grubman JMarvin, Baxt Barry: Molecular basis of pathogenesis of FMDV. Virus Research 2003, 91:29-32.

24. McCullough KC, Sobrino F: Immunology of foot-and-mouth disease. Foot and Mouth Disease: Current Perspectives 2004. Horizon Bioscience, Wymondham, Norfolk, England 173-222.

25. De Groot SAnne, Sbai Hakima, Aubin Saint Caitlin, McMurry Julie, Martin William: Immuno-informatics: Mining genomes for vaccine components. Immunology and Cell Biology 2002, 80:255-269.

26. Gao Yan-feng, Sun Zhan-qiang, Qi Feng, Qi Yuan-ming, Zhai Ming-xia, Lou Hui-ping, Chen Li-xiang, Li Yong-xin, Wang Xian-yuan: Identification of a new broad-spectrum $\mathrm{CD}^{+} \mathrm{T}$ cell epitope from over-expressed antigen COX-2 in esophageal carcinoma. Cancer Letters 2009, 284:55-61.

27. Ochoa-Callejero L, Otano I, Vales A, Olagüe C, Sarobe P, Lasarte JJ, Prieto J, Menne S, González-Aseguinolaza G: Identification of $\mathrm{CD}^{+}$and $\mathrm{CD}^{+} \mathrm{T}$ cell epitopes of woodchuck hepatitis virus core and surface antigens in BALB/c mice. Vaccine 2010, 28:5323-5331.

28. Lin Xu'ai, Zhao Jinfang, Qian Jing, Mao Yafei, Pan Jianping, Li Liwei, Peng Huiqin, Luo Yihui, Yan Jie: Identification of Immunodominant B- and T-Cell Combined Epitopes in Outer Membrane Lipoproteins LipL32 and LipL21 of Leptospira interrogans. Clinical and Vaccine Immunology 2010, 17:778-783.

29. Suzuki Daisuke, Nagata Toshi, Eweda Ghada, Matsumoto Sohkichi, Matsumoto Makoto, Tsujimura Kunio, Koide Yukio: Characterization of murine T-cell epitopes on mycobacterial DNA-binding protein 1 (MDP1) using DNA vaccination. Vaccine 2010, 28:2020-2025.

30. Yokouchi H, Chamoto K, Wakita D: Tetramer-blocking assay for defining antigen-specific cytotoxic T lymphocytes using peptide-MHC tetramer. Cancer Sci 2006, 97(2):148-154.

31. Zhou M, Peng J, Zhang $\mathrm{H}$ : Identification of two naturally presented MAGE antigenic peptides from a patient with hepatocellular carcinoma by mass spectrometry. Immunol Lett 2005, 99(1):113-121.

32. Jaramillo A, Majumder K, Manna P: Identification of HLA-A3-restricted CD8 ${ }^{+} \mathrm{T}$ cell epitopes derived from mammaglobin-A, a tumor-associated antigen of human breast cancer. Int J Cancer 2002, 102(5):499-506.

33. Gricks C, Rawlings E, Foroni L: Somatically mutated regions of immunoglobulin on human B-cell lymphomas code for peptides that bind to autologous major histocompatibility complex class I, providing a potential target for cytotoxic T cells. Cancer Res 2001, 61(13):5145-5152.

34. Kunisawa T, Kanaya S, Kutter E: Comparison of synonymous codon distribution patterns of bacteriophage and host genomes. DNA Res 1998 5(6):319-321.

35. Gouy M: Codon contexts in enterobacterial and coliphage genes. Mol Bio Evol 1987, 4(4):426

36. Nishida K, Kawasaki T, Fujie M: Aminoacylation of tRNAs encoded by Chlorella virus CVK2. Virology 1999, 263(1):220.

37. Deng Y, Yewdell JW, Eisenlohr LC, Bennink JR: MHC affinity, peptide liberation, $\mathrm{T}$ cell repertoire, and immunodominance all contribute to the paucity of MHC class I-restricted peptides recognized by antiviral CTL. J Immunol 1997, 158(4):1507-1515.

38. Sette A, Vitiello A, Reherman B, Fowler P, Nayersina R, Kast WM, Melief CJ, Oseroff C, Yuan L, Ruppert J: The relationship between class I binding affinity and immunogenicity of potential cytotoxic T cell epitopes. J Immunol 1994, 153(12):5586-5592.

39. Schmittel A, Keilholz U, Bauer S, Kuhne U, Stevanovic S, Thiel E, Scheibenbogen C: Application of the IFN-gamma ELISPOT assay to quantify T cell responses against proteins. J Immunol Methods 2001, 247(1-2):17-24.

40. Quiding M, Granstrom G, Nordstrom I, Ferrua B, Holmgren J, Czerkinsky C: High frequency of spontaneous interferon-gamma-producing cells in human tonsils: role of local accessory cells and soluble factors. Clin Exp Immunol 1993, 91(1):157-63.

41. Mason WPeter, Grubman JMarvin, Baxt Barry: Molecular basis of pathogenesis of FMDV. Virus Research 2003, 91:29-32.

42. Domingo Esteban, Escarmís Cristina, Baranowski Eric, Ruiz-Jarabo MCarmen, Carrillo Elisa, Núñez Ignacio Juan, Sobrino Francisco: Evolution of foot-andmouth disease virus. Virus Research 2003, 91:47-63. 
43. Knowles NJ, Samuel AR: Molecular epidemiology of foot-and-mouth disease virus. Virus Research 2003, 91:65-80.

44. KC Parker, Bednarek MA, Coligan JE: Scheme for ranking potential HLA-A2 binding peptides based on independent binding of individual peptide side-chains. J Immunol 1994, 152:163-167.

doi:10.1186/1743-422X-8-426

Cite this article as: Liu et al:: Identification of $\mathrm{H}-2 \mathrm{~d}$ Restricted T Cell

Epitope of Foot-and-mouth Disease Virus Structural Protein VP1. Virology Journal 2011 8:426.

Submit your next manuscript to BioMed Central and take full advantage of:

- Convenient online submission

- Thorough peer review

- No space constraints or color figure charges

- Immediate publication on acceptance

- Inclusion in PubMed, CAS, Scopus and Google Scholar

- Research which is freely available for redistribution 